\title{
PENGARUH VARIASI SUDUT PRIMARY PULLEY PADA TRANSMISI SEPEDA MOTOR SCOOPY 110 CC TAHUN 2014 TERHADAP DAYA DAN TORSI
}

\author{
HENDRA HARSANTA ${ }^{1}$ PARTA $^{2}$ \\ ${ }^{1,2}$,Program Studi Teknik Mesin, Fakultas Teknik, Universitas Muhammadiyah Tangerang \\ Jl. Perintis Kemerdekaan I/33 Cikokol-Tangerang \\ E-mail:hharsanta@ymail.com
}

\begin{abstract}
ABSTRAK
Dalam kehidupan sehari-hari bidang kegiatan transportasi sangat penting, secara umum diartikan sebagai perpindahan barang atau orang dari satu tempat ketempat lain. Seiring dengan peningkatan kebutuhan masyarakat dan semakin meningkatnya jumlah penduduk, maka aktivitas transportasipun juga meningkat. Dengan transportasi yang lancar maka distribusi barang dan jasa juga akan semakin mudah. Penelitian ini bertujuan untuk mengetahui pengaruh variasi sudut primary pulley pada transmisi sepeda motor scoopy 110 cc tahun 2014 yang responsive untuk mengetahui pengaruh sudut kemiringan primary pulley dari sudut pulley standart dipakai $15,5^{\circ}$ menjadi $12^{\circ}$ dan $13^{\circ}$. Pulley adalah komponen terpenting dalam motor matic yang berguna untuk memindahkan kecepatan yang sudah sesuai dengan RPM pada mesin secara otomatis tanpa menggunakan gigi transmisi. melainkan menggunakan v-belt sebagai penghubung atau penerus putaran yang terjadi pada kedua pulley. Hasil penelitian untuk mengetahui pengaruh variasi sudut kemiringan primary pulley $12^{\circ}$ dan $13^{\circ}$ terhadap daya dan torsi. Dengan menggunakan sudut Primary Pulley 12 pada kecepatan rpm 6000 menghasilkan $4 \mathrm{Hp}$ dan 5,42 Nm. Nm dan sudut Primary Pulley $13^{\circ}$ pada kecepatan rpm rpm 6000 menghasilkan 7,9 Hp dan 9,35 Nm.
\end{abstract}

Kata kunci: Primary Pulley; Pulley; Dynotest, Primary Pulley $12^{\circ}$, Primary Pulley $13^{\circ}$

\begin{abstract}
In everyday life, the field of transportation activities is very important, generally defined as the movement of goods or people from one place to another. Along with the increasing needs of the community and the increasing number of residents, transportation activities also increase. With smooth transportation, the distribution of goods and services will also be easier. This study aims to determine the effect of variations in the primary pulley angle on a responsive 110 cc scooter transmission in 2014 to determine the effect of the primary pulley tilt angle from a standard pulley angle of $15.5^{\circ}$ to $12 \mathrm{o}$ and $13^{\circ}$. Pulley is the most important component in the automatic motor that is useful for moving the speed that is in accordance with the RPM on the engine automatically without using the transmission gear. instead, using a v-belt as a link or successor to the rotation that occurs on both pulleys. The results of the study were to determine the effect of variations in the angle of the primary pulley $12 \mathrm{o}$ and $13 \mathrm{o}$ on power and torque. By using the Primary Pulley 12 angle at a speed of $6000 \mathrm{rpm}$ to produce $4 \mathrm{Hp}$ and $5.42 \mathrm{Nm}$. Nm and Primary Pulley angle of $13 \mathrm{o} \mathrm{at} 6000 \mathrm{rpm}$ speed produces $7.9 \mathrm{HP}$ and $9.35 \mathrm{Nm}$.
\end{abstract}

Keywords: Primary Pulley; Pulley; Dynotest, Primary Pulley $12^{\circ}$, Primary Pulley $13^{\circ}$

\section{PENDAHULUAN}

Sepeda motor merupakan salah satu alat transportasi yang banyak dipakai oleh masyarakat Indonesia. Hal ini disebabkan karena sepeda motor merupakan alat transportasi yang mudah untuk dikendarai dan juga lebih terjangkau oleh masyarakat kita bila dibandingkan dengan mobil pribadi. (Muhammad Abi Berkah Nadi,2018:138).

Pada sepeda motor matic seperti honda scoopy, sistem pemindah tenaga atau transmisinya tidak menggunakan perpindahan roda gigi (manual), melainkan menggunakan transmisi otomatis, pada kendaraan yang menggunakan transmisi otomatis pengoperasiannya tidak menggunakan perpindahan roda gigi melainkan menggunakan pulley dan sabuk (belt) yang dikenal dengan CVT (Continuous Variable Transmission). Sistem CVT (Continuous Variable Transmission) adalah sistem transmisi daya dari mesin menuju roda belakang melalui sabuk V ( $V$-belt $)$ yang menghubungkan antara drive pulley (puli primer) untuk menggerakkan driven pulley (puli sekunder) menggunakan gaya sentrifugal yang terjadi pada komponenkomponennya. Perubahan kecepatan pada CVT 
sangat halus dan tidak ada hentakan seperti pada transmisi manual. Mekanisme yang memindahkan tenaga adalah poros engkol langsung mengopel primary pulley (drive pulley) dan drive belt ( $V$-belt) digunakan untuk memutar secondary pulley (driven pulley).

\section{METODOLOGI PENELITIAN}

Metode penelitian dengan eksperimen dimana metode yang digunakan untuk mengetahui sebab akibat (hubungan kausal) terhadap dua faktor dan secara sengaja ditimbulkan, oleh peneliti dengan tidak menghadirkan terlalu banyak faktor-faktor yang dapat mengganggu. Hasil yang berupa data dari proses pengujian kemudian dilakukan verifikasi dengan literatur yang ada dan dilakukan analisa penelitian.

Pulley adalah komponen terpenting dalam motor matic yang berguna untuk memindahkan kecepatan yang sudah sesuai dengan RPM pada mesin secara otomatis tanpa menggunakan gigi transmisi. melainkan menggunakan vanbelt sebagai penghubung atau penerus putaran yang terjadi pada kedua pulley. ( Gede Tangkas Arta Susena dkk. 2017.)

Ada 3 cara prinsip kerja pada pulley adalah sebagai berikut :

1. Saat Kecepatan Torsi

Pada Tahap ini, torsi sangat dibutuhkan, sehingga Drive Pulley mengecil untuk mendapatkan torsi yang diinginkan.

2. Putaran Menengah

Pada Tahap ini, mulai beralih kepada kebutuhuan 'kecepatan', sehingga Drive Pulley, berangsur angsur bergerak melebar, dan Driven pulley bergerak mengecil.

3. Putaran Tinggi.

Pada tahap ini, "Kecepatan" dari mesin sangat dibutuhkan sehingga mendorong Drive Pulley semakin melebar dan driven pulley semakin mengecil. (Anonim. Primary Pulley. 2017)

\section{HASIL DAN PEMBAHASAN}

Hasil pengujian sudut kemiringan pada primary pulley $15,5^{\circ}$ (Pulley Standar) motor automatic fuel injection $110 \mathrm{cc}$ berupa daya yang didapat melalui pengujian dengan menggunakan alat dynotest, data hasil spesifikasi variasi sudut primary pulley standar yang telah dilakukan pengujian. Peneliti mengambil dasar penetapan rpm 5500, 6000, 6500 . Peneliti mengambil data rpm awal 5500 dikarenakan pada rpm tersebut memiliki data yang lebih valid daripada rpm rendah, karena pada rpm rendah data rpm yang dihasilkan sering berubahubah. Dasar untuk data pengaruh variasi sudut primary pulley $\mathrm{rpm}$ peneliti mengambil kecepatan rpm 6000 dikarenakan pada rpm tersebut sudah bisa menunjukan data yang signifikan. Berikut tabel 4.1 hasil pengujian dengan sudut primary pulley standart $15,5^{\circ}$.

Tabel 1. Pengujian dengan Sudut $15.5^{\circ}$.

\begin{tabular}{|c|c|c|}
\hline $\begin{array}{c}\mathrm{n}, \\
(\mathrm{rpm})\end{array}$ & $\begin{array}{c}\text { Daya, } \\
\mathrm{P}(\mathrm{Hp})\end{array}$ & $\begin{array}{c}\text { Torsi, } \\
\mathrm{T}(\mathrm{Nm})\end{array}$ \\
\hline 5500 & 2 & 2,71 \\
\hline 6000 & 6,9 & 8,54 \\
\hline 6500 & 9,2 & 9,49 \\
\hline 7000 & 8 & 8,13 \\
\hline 7500 & 7,9 & 7,45 \\
\hline 8000 & 8 & 6,77 \\
\hline 8500 & 7 & 5,83 \\
\hline 9000 & 7 & 5,42 \\
\hline 9500 & 5,2 & 4,06 \\
\hline
\end{tabular}

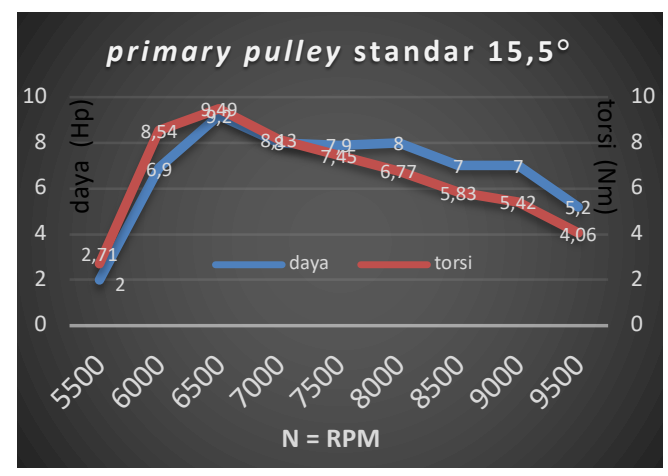

Gambar 1. Grafik Primart Pulley Standart $15.5^{\circ}$

\section{Pengaruh Sudut Kemiringan Primary Pulley $12^{\circ}$ Terhadap Daya dan Torsi pada Sepeda Motor Scoopy}

Hasil pengujian sudut kemiringan pada sudut primary pulley $12^{\circ}$ motor automatic fuel injection $110 \mathrm{cc}$ dimana daya yang didapat melalui pengujian dengan menggunakan alat dynotest, Berikut tabel 4.2 data hasil spesifikasi variasi sudut primary pulley $12^{\circ}$ yang telah dilakukan pengujian sebagai berikut :

Tabel 2. Pengujian dengan Sudut $12^{\circ}$.

\begin{tabular}{|c|c|c|}
\hline $\begin{array}{c}\mathbf{n}, \\
\text { ( rpm })\end{array}$ & $\begin{array}{c}\text { Daya, } \\
\mathbf{P}(\mathbf{H p})\end{array}$ & $\begin{array}{c}\text { Torsi, } \\
\mathbf{T}(\mathbf{~ N m})\end{array}$ \\
\hline 5500 & 2,3 & 3,11 \\
\hline 6000 & 4 & 5,42 \\
\hline 6500 & 7,2 & 7,86 \\
\hline 7000 & 7,9 & 8,13 \\
\hline
\end{tabular}




\begin{tabular}{|c|c|c|}
\hline 7500 & 8,1 & 7,45 \\
\hline 8000 & 7,9 & 6,77 \\
\hline 8500 & 7,1 & 6,10 \\
\hline 9000 & 7 & 5,55 \\
\hline 9500 & 5,3 & 4,06 \\
\hline
\end{tabular}

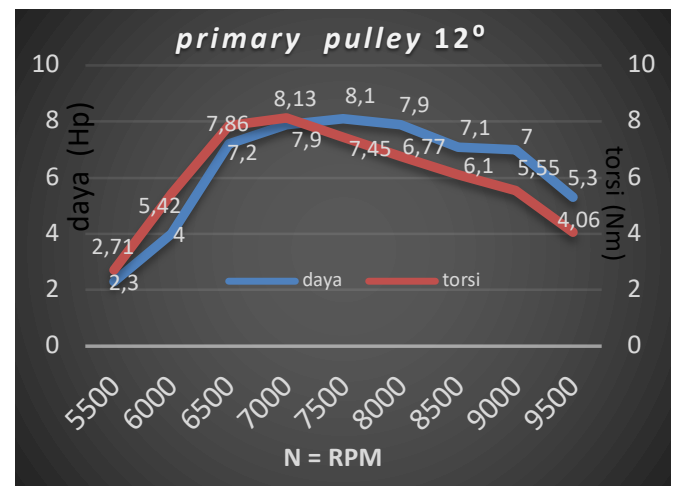

Gambar 2. Grafik Primart Pulley Standart 12。

Setelah dilakukannya pengujian oleh dengan uji dynotest untuk mengetahui daya dan torsi dengan menggunakan sudut primary pulley $12^{\circ}$. Berdasarkan grafik tersebut diatas, pada rpm 5500 sampai 7500 mengalami kenaikan daya (Hp) yang cukup tinggi dikarenakan di rpm tersebut daya motor masih memiliki tenaga yang cukup maksimal, sedangkan pada rpm 8000 sampai 9500 daya dan torsi cenderung mengalami penurunan hal ini disebabkan tenaga motor sudah mencapai batas maksimal sehingga daya dan torsi motor mengalami penurunan.

\section{Pengaruh Sudut Kemiringan Primary}

Pulley $1^{\circ}$ terhadap Daya dan Torsi pada Sepeda Motor Scoopy.

Hasil pengujian sudut kemiringan pada primary pulley $13^{\circ}$ motor automatic fuel injection $110 \mathrm{cc}$, dimana daya yang didapat melalui pengujian dengan alat uji dynotest, merupakan data hasil spesifikasi variasi sudut primary pulley $13^{\circ}$ yang telah dilakukan pengujian, Berikut pada Tabel 3 data hasil pengujian .

Pada hasil uji dynotest untuk mengetahui daya dan torsi dengan menggunakan sudut primary pulley $13^{\circ}$. Berdasarkan grafik tersebut diketahui bahwa pada rpm 5500 sampai 6500 mengalami kenaikan daya (Hp) yang cukup tinggi, dikarenakan di rpm tersebut daya motor masih memiliki tenaga yang cukup maksimal, sedangkan pada rpm 7000 sampai 9500 daya dan torsi cenderung mengalami penurunan hal ini disebabkan tenaga motor sudah mencapai batas maksimal sehingga daya dan torsi motor mengalami penurunan.

Tabel 3. Pengujian dengan Sudut $13^{\circ}$

\begin{tabular}{|c|c|c|}
\hline $\begin{array}{c}\text { n, } \\
\text { ( rpm ) }\end{array}$ & $\begin{array}{l}\text { Daya, } \\
\text { P ( Hp ) }\end{array}$ & $\begin{array}{l}\text { Torsi, } \\
\text { T ( Nm ) }\end{array}$ \\
\hline 5500 & 2,8 & 3,11 \\
\hline 6000 & 7,9 & 5,42 \\
\hline 6500 & 8,5 & 8,81 \\
\hline 7000 & 8,1 & 8,13 \\
\hline 7500 & 7,8 & 7,32 \\
\hline 8000 & 7,5 & 6,64 \\
\hline 8500 & 6,8 & 5,28 \\
\hline 9000 & 6,5 & 5,28 \\
\hline 9500 & 5,3 & 4,06 \\
\hline
\end{tabular}

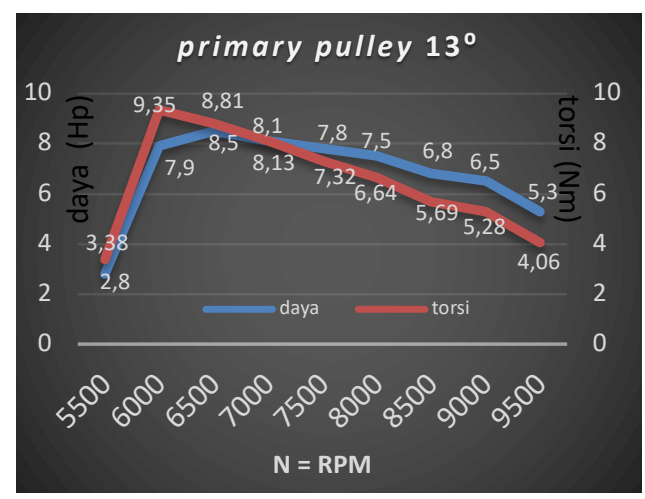

Gambar 3. Grafik Primart Pulley Standart $13^{\circ}$

\section{KESIMPULAN}

Dari data-data hasil pengujian dengan variasi sudut kemiringan pada primary pulley $15,5^{\circ}$ (pulley standar), $12^{\circ}$ dan $13^{\circ}$ pada motor automatic fuel injection $110 \mathrm{cc}$ dengan pengujian dynotest, dapat disimpulkan sebagai berikut :

1. Hasil pengujian dengan menggunakan sudut primary pulley $15,5^{\circ}$ (standar), pada kecepatan $6000 \mathrm{rpm}$, diperoleh daya $6,9 \mathrm{Hp}$ dan torsi 8,54 
$\mathrm{Nm}$. Pada kecepetan rpm tersebut terlihat pada midle speed terjadi perubahan dan berpengaruh yang signifikan terhadap daya dan torsi.

2. Hasil pengujian dengan menggunakan sudut primary pulley $12^{\circ}$, pada kecepatan $6000 \mathrm{rpm}$, diperoleh daya $4 \mathrm{Hp}$ dan torsi 5,42 Nm. Pada kecepatan rpm tersebut berpengaruh pada midle speed terlihat midle speed terjadi penurunan di bandingkan dengan hasil pada primary pulley pada $15,5^{\circ}$.

3. Hasil pengujian dengan sudut primary pulley $13^{\circ}$, pada kecepatan $6000 \mathrm{rpm}$, diperoleh daya 7,9 Hp dan torsi 9,35 Nm. Pada kecepatan rpm tersebut berpengaruh terhadap midle speed, dimana hasil menunjukkan adanya peningkatan / kenaikan yang signifikan, dibandingkan dengan hasil pada pada primary pulley pada $15,5^{\circ}$ dan $12^{\circ}$.

4. Dengan data-data hasil pengujian, maka dapat disimpulkan bahwa dengan menggunakan variasi sudut primary pulley $13^{\circ}$, pada kecepatan di $6000 \mathrm{rpm}$ dapat perpengaruh dan dapat memberikan midle speed, yang lebih baik dimana hal ini akan memberikan acceleration yang unggul di banding dengan menggunakan sudut primary pulley $15,5^{\circ}$ dan $12^{\circ}$.

\section{DAFTAR PUSTAKA}

Adi Wahyu. (2012). pengembangan media pembelajaran continuous variable transmission (cvt) sepeda motor menggunakan macromedia flash untuk pembelajaran di SMK Muhammadiyah 1 Bambang Lipuro Bantul. Skripsi. Yogyakarta: FT Universitas Negeri Yogyakarta.

Anonim. Primary Pulley. Diperoleh 28 September 2017

Anonim. Spesifikasi Motor Scoopy Fi 2014. Diperoleh 2 September 2017

Gede Tangkas Arta Susena dkk. 2017. pengaruh sudut primary pulley dan variasi berat roller terhadap torque dan rpm pada motor ganesha electric vehicles 1.0 base continous variable transmision (cvt). Jurnal Jurusan Pendidikan Teknik Mesin (JJPTM) Volume: 7 No : 1.

Hidayat, Wahyu. (2015). Trans-Matic Pemindah Daya Kendaraan. Jakarta: Rineka Cipta.

Hidayat, Wahyu. (2012) . Motor Bensin Modern. Jakarta: Rineka Cipta.

Kristanto, Philip. (2015). Motor Bakar Torak. Yogyakarta: Andi Yogyakarta.

Marsudi. (2016). Teknisi Otodidak Sepeda Motor Matic. Yogyakarta: Andi Yogyakarta.

Maskurmambang. (2011). Akselerasi dan Torsi. Diperoleh 18 September 2017 